\title{
POLICÍA Y CIENCIA DE LA POLICÍA EN EL DISCURSO URBANÍSTICO A FINALES DEL ANTIGUO RÉGIMEN
}

\author{
Alfonso Zarzoso \\ Institut Universitari d'Història Jaume \\ Vicens i Vives. Universitat Pompeu Fabra. Barcelona (España)
}

\begin{abstract}
Pedro Fralle, La otra ciudad del Rey. Ciencia de la Policía y Organización urbana en España, Madrid, Celeste Ediciones, 1997, 152 pp.

Ricardo ANGUITA CANTERO, Ordenanza y Policía Urbana. Los orígenes de la reglamentación edificatoria en España (1750-1900); Granada, Universidad de Granada / Junta de Andalucía, 1997, 387 pp.
\end{abstract}

Tal vez resulte extraña la inclusión, en una revista de historia de la medicina y de la ciencia, de una reseña sobre dos libros dedicados a conocer el discurso urbanístico, su evolución y transformación, anterior a los cambios urbanos originados por la sociedad industrial del siglo XIX. Sin embargo, como veremos, tal inclusión se puede fundamentar en las múltiples vías de estudio que abren para la historia de la medicina. Por ejemplo, con relación al ambientalismo hipocrático, a la información médica de determinados expertos locales, a la idea de policía médica, al movimiento higienista o a la ética y responsabilidad de los médicos ligados a las transformaciones urbanas de los siglos XVIII y XIX. Por ello, creemos que su lectura, desde el punto de vista de la historia de la medicina, debería constituir un acicate para reflexionar sobre dichas líneas de trabajo y para llevar a cabo los indispensables análisis de las diferentes realidades urbanas peninsulares.

El libro de Pedro Fraile, especialista en Geografía Humana, intenta responder a la concepción rupturista que situaba a partir del desarrollo de la sociedad industrial las bases del pensamiento urbanístico, ignorando la tradición anterior, en esta materia, especialmente desde finales del siglo XVII. Para ello recurre al estudio de una selección, por otra parte escasamente definida, de la producción tratadística española de lo que dicho autor denomina como Ciencia de la Policía, lo que constituye un nuevo acercamiento que debe destacarse. Se trata de un primer intento sistematizador de obras generales que sitúan los temas y metodologías de la materia. De ahí que, de momento, no desciende al estudio de la realidad práctica municipal relacionada con aquella ciencia, ni se complementa con la gran producción dispersa sobre policía.

El estudio se estructura en siete capítulos. El primero de ellos está dedicado al Traité de la Policie (1705-38, 4 vols.) de Nicolás Delamare, que fue obra de referencia y de gran repercusión en la 


\section{ENSAYOS}

Europa del siglo XVIII, y que sirve para presentar los elementos de la ciencia de la policía. El segundo aborda la producción autóctona, anterior al siglo XVIII, utilizando las obras de los castellanos Castillo de Bobadilla (1597), Fernández Navarrete (1619) y Saavedra Fajardo (1659). Obras que considera básicas para el desarrollo peninsular de la ciencia de la policía en tanto configuraron de manera general una especificidad propia. Los capítulos tercero y cuarto presentan la tratadística de dicha ciencia en la España de los siglos XVIII y XIX. Así, en primer lugar, caracteriza el entorno científico, social y político en que aquélla hace eclosión, esto es, bajo el reinado de Carlos III. Un período caracterizado por cierta renovación científica, en el que destaca también un gobierno preocupado por el estado de las ciudades y por la necesidad de formar élites en ciencia de la administración. En segundo lugar, presenta la reflexión específica en materia de policía, destacando sus contenidos y objetivos, a partir de los trabajos originales o traducidos de dos grupos de autores: por un lado la traducción de las Institutions Politiques de Bielfeld (1760) realizada por Domingo de la Torre (1767-1801), Las señales de la felicidad... escrita por Frances Româ Rosell (1768), la traducción de la obra escrita por el médico portugés Antonio Ribeiro (1757, Tratado de la conservación de la salud de los pueblos ..., llevada a cabo por el matemático y arquitecto Benet Bails (1781), y la traducción de la versión francesa de los Grundsätze der Polizei-Wissenschaft... (o Éléments généraux de policie...) de Justi (1756) efectuada por Francesc Puig Gelabert (1784). El segundo grupo está formado por las Cartas sobre la policía redactadas por Valentín de Foronda (1801) y la traducción de la obra citada de Delamare (1705-30) incluida en el extenso trabajo de Tomás de Valeriola (1798-1805). En los capítulos quinto y sexto, Fraile trata de recuperar, a partir de las obras citadas, la aportación de la ciencia de la policía en relación con el discurso urbanístico. Aquí, la multiplicidad de ámbitos que comprende esta ciencia, así como su unión tanto a la cotidianeidad de la vida urbana como a la intervención sobre las actividades de los individuos, lleva al autor a interpretar aquélla en función de la teoría foucaultiana de disciplina, encuadramiento y configuración de actitudes, esto es, la «cara modernizadora de los tratados de policía» (p. 77). Por otra parte, traza un cuadro general de las cuestiones planteadas por dichos autores en relación con una visión globalizadora, racional y cerrada, de la ciudad, en la cual se hallarían elementos fundamentales en la reflexión sobre la morfología urbana en el siglo XIX. En el último capítulo, Fraile utiliza dos textos, escritos por Ortiz Zúñiga (1841) y por Fossas i Pi (1872), para mostrar el proceso de desintegración de la ciencia de la policía y su especialización (higienismo, èstadística social, etc.) en manos de otros profesionales (médicos, arquitectos, ingenieros), a la par que el nuevo orden burgués imponía un nuevo modo de organizar la sociedad. Finalmente, el libro recoge una larga y ejemplar, aunque incompleta, relación de trabajos ligados a la ciencia de la policía, escritos en España entre los siglos XVII y XIX.

El trabajo de Ricardo Anguita, resultado de su tesis doctoral en historia del arte, desciende del discurso teórico a la práctica cotidiana, si bien permanece ligado al material escrito de la ordenanza municipal. En este sentido, Anguita hace un esfuerzo importante al estudiar un buen número de diferentes articulados ordenancistas municipales. Este uso de la ordenanza como objeto de análisis histórico le permite llevar a cabo un estudio evolutivo de la reglamentación edificatoria hispánica desde la baja Edad Media hasta el siglo XIX, en el marco de las competencias municipales en materia de policía urbana aplicadas a la ciudad histórica. Por tal marco de trabajo entiende la estructura urbana conformada en la época medieval y transformada por el Antiguo Régimen hasta su cambio global en la segunda mitad del siglo XIX.

El libro se estructura en tres partes en función de una división temporal. Cada una de ellas se subdivide en forma general en otros tres apartados, donde se estudian sucesivamente el régimen municipal y sus competencias, la reglamentación edificatoria derivada de las ordenanzas promul- 


\section{ENSAYOS}

gadas y los oficiales e instituciones encargadas de la observancia de dicha reglamentación local. Este procedimiento se aplica, en la primera parte, al estudio de la reglamentación edificatoria en la ciudad romana, musulmana, cristiana y pre-ilustrada. Destaca el tránsito de la regulación desde las servidumbres prediales o vecinales en la ciudad romana a una preocupación, iniciada, tras un largo proceso de desurbanización alto medieval, en la ciudad musulmana y mantenida hasta finales del Antiguo Régimen, por la protección del espacio de calle. Esto es, la preocupación por el trazado de calle basada en la búsqueda de mayor seguridad y mejor tránsito. Cabe señalar la importancia fundamental de los oficiales procedentes de la Hisba musulmana, el muhtasib (almotacén de la corona castellana o mustassaf de la aragonesa) y el arif (alarife castellano o maestros de obras aragoneses) por cuanto serán asimilados por la ciudad cristiana al igual que sus competencias, ampliándolas a la higiene de las calles en tanto cabía favorecer la libre circulación del aire y la entrada de la luz. La descripción de un nuevo mecanismo de intervención en la trama urbana a partir del siglo XVI, las alineaciones de casas haciéndolas coincidir con el momento de su reedificación, se completa a partir del seguimiento ordenancístico moderno.

En la segunda parte, dedicada a la ciudad ilustrada, Anguita muestra cómo los fundamentos anteriores de seguridad, tránsito e higiene se complementan con la implantación del ornato mediante el ideal del aspecto público. Para observar este nuevo ideal y garantizar el control del espacio urbano. Anguita introduce el tema de la influencia de la Polizeiwissenschaft, o ciencia de la policía, desarrollada por Delamare y Justi (p. 106) para conseguir el bienestar de los ciudadanos a través de la mejora de las condiciones de la vida urbana. Esto le lleva a hablar, sin conseguir demostrarlo, de la creación borbónica de una estructura policial urbana (Alcaldes de Barrio, Sindicatos Personeros, etc), cuya «falta había originado hasta entonces el fracaso de cualquier intento de controlar la actividad edificatoria pese a la abundante formación de ordenanzas sobre la materia» (p.128). En este sentido, y ligado al proceso de centralización administrativa borbónica, pasa a analizar la creación de la Real Academia de Bellas Artes de San Fernando (1744-52), que encajaría en un proceso de institucionalización de la enseñanza y de imposición de un patrón artístico, mediante la formación de arquitectos titulados y el control de las licencias de obras. Sin embargo, en mi opinión, la nueva institución se añadió al listado acumulativo de instancias implicadas en esta materia, tropezando con la ya vigente maquinaria administrativa y constituyendo así parte de la característica típica del reformismo ilustrado borbónico. Por otra parte, Anguita observa cómo el canon ilustrado uniformizador del aspecto público exterior de los edificios (planos de fachada) tan sólo sería recogido en unos reglamentos ordenancísticos municipales de finales de siglo. Finalmente, cabe destacar el tránsito, no sin razón iniciado en Barcelona (regulaciones de 1762 y 1771), del procedimiento tradicional de alineación de casas en el momento de la reedificación a la alineación de calles previa decisión de la línea de edificación. Esta búsqueda de un continuum arquitectónico se completará con el inicio, también en Barcelona, del control de la altura de los edificios, lo cual se ligaría con la idea de salud publica informada por la teoría médica de la libre circulación aérea.

La tercera parte se centra en la transformación urbanística y arquitectónica de la ciudad histórica anterior al ensanche de las grandes urbes. Mientras en el primer tercio del siglo XIX se habían vivido los estertores del Antiguo Régimen y la pervivencia en los escasos reglamentos renovados de las regulaciones ilustradas, los nuevos Ayuntamientos constitucionales son claves para interpretar la transformación urbana que se sucedió, debido al mantenimiento bajo su control de la actividad edificatoria y urbanística. De este modo, Anguita señala cómo, más allá de la creación de una Junta Consultiva de Policía Urbana (1752), interventora estatal de las cada vez más homogéneas ordenanzas municipales en materia edificatoria, la ola liberal que recorre este período no sólo no estableció un código general de construcción, sino que se inhibió ante la competencia del pro- 
pietario en cuanto a la edificabilidad interior, contribuyendo a la insalubridad en las habitaciones, a pesar de la mención específica del factor higiene como argumento en contra. Por otra parte, Anguita destaca una serie de ciudades, encabezadas casi siempre por Barcelona y Cádiz, que introdujeron en sus reglamentos de la primera mitad de siglo medidas relacionadas con mínimos de altura por piso y con la regulación de la altura de las casas en función del ancho de calle. La tendencia a la verticalidad constructora, espoleada por la presión demográfica, contribuyó a su vez al deterioro higiénico de las viviendas. Por ello, dichas medidas estuvieron ligadas a la idea de salud pública, aunque acabarían enfrentándose con lo que se convirtió en el primer parámetro de edificabilidad, la rentabilidad del suelo urbano. En dichos reglamentos también se hallan los elementos fundamentales del procedimiento de declaración de ruina y expropiación forzosa en nombre de la utilidad pública, como instrumentos legales de renovación arquitectónica. $\mathrm{O}$ los puntuales intentos fracasados de levantamiento de planes generales de alineación de calles y plazas. Fórmulas que fueron recogidas por la legislación nacional a partir de la mitad de siglo, cuando la ciudad desigual ya había arraigado.

Una vez señalados los aspectos tratados en ambos libros, puede resultar útil hacer una valoración de su aportación en conjunto. Desde mi punto de vista, cabe destacar su complementariedad como muestra el recurso a trabajos teóricos y a las ordenanzas municipales con el objetivo final de comprender el proceso histórico que condujo a la aparición de la disciplina urbanística en el último tercio del siglo XIX. Con todo, más allá de la corresponsabilidad entre teoría y práctica o entre realidad diaria y la ley u ordenanza que la sanciona, sería interesante pasar a analizar la cotidianeidad administrativa urbana de forma monográfica con el fin de conocer mejor el proceso de construcción de la ciudad y la influencia que teorías médicas y profesionales sanitarios desempeñaron en aquél.

Con el fin de fundamentar su discurso, Fraile y Anguita recurren a los conceptos derivados del cameralismo germánico. Sin embargo, tanto la constante confusión terminológica de Fraile entre policía y ciencia de la policía, como su significativo recurso a la obra ejemplar de Delamare, así como la confusión similar de Anguita al hablar de policía urbana o al introducir la idea de estructura policial, más propia de la función genérica de orden público creada a principios del siglo XIX, muestran la necesidad de profundizar en la reflexión teórica en la que se han basado'. En mi opinión, no se puede confundir policía y ciencia de la policía, ni utilizar erróneamente a los autores que difunden o utilizan estos conceptos para crear un discurso alejado de la realidad en la que se inscriben. La materia de la policía era infinita puesto que debía regular todos los aspectos de la vida social y económica que escapaban de la autorregulación de la sociedad de órdenes estamentales. Por supuesto, Nicolás Delamare era un conspicuo representante de esta idea de policía y así se demuestra en su extenso trabajo dedicado al buen gobierno y a la consecución del bienestar de la población, pero en el que todavía no se ha racionalizado el Antiguo Régimen. Considero que es así como debe entenderse la traducción que de dicho autor hace Valeriola. Cabría asimilar esta policía con las regulaciones recogidas desde la época medieval en las ordenanzas municipales, las cuales permanecieron como un modelo prescriptivo de un orden social. La elaboración de dicho modelo

1 Sobre este tema, véase: Pierangelo Schiera, La dinamica statale austriaca nel XVIII e XIX secolo: strutture e tendenze di storia constituzionale prima e dopo Maria Teresa, Bolonia, Il Mulino, 1981; M. Raeff, The Well-Ordered Policie State. Social and Institutional Change through Law in the Germanies and Russia. 1600-1800, New Haven, Yale University Press, 1983; y los trabajos de Keith Tribe, Governing Economy. The Reformation of German Economic Discourse 1750-1840, (Cambridge, Cambridge University Press, 1988; «Cameralism and the Science of Government» in Journal of Modern History, 56 (1984), 263-284. 


\section{ENSAYOS}

fue tarea de la Polizeiwissenschaft germánica, especialmente de la mano de Justi, Bielfeld, Sonnenfels y otros. La ciencia de la policía, preocupada por las actividades comprendidas en la gute Polizei, se convierte así en una rama de la Staatwissenschaft o ciencia del gobierno, que a su vez había sido impulsada en Prusia a principios del siglo XVIII por la universitaria Kammeralwissenschaft o ciencia de la administración económica. Éste fue un proyecto desarrollado en las universidades prusianas del setecientos y jugó un papel clave en la evolución de las formas de burocracia (oficiales del estado) ligadas a la necesidad de una administración efectiva para poder aumentar el poder del estado. Así, la diferencia es substancial. Por ello no se puede recurrir de forma indiscriminada a los autores españoles que tratan, traducen y comentan una u otra idea. De esta forma, se echa de menos una lectura atenta de los trabajos de Ernest Lluch, quien lleva reflexionando sobre este tema cerca de treinta años ${ }^{2}$. En este sentido, las obras de Rom Rossel, De la Torre, Puig Gelabert, Foronda y tantos otros, vascos o de la Corona de Aragón, se alejan de la idea general de policía ligada a Delamare y toman como guía la teoría prusiana de Bielfeld y Justi, bien para elaborar un programa global y alternativo de policía y economía ante el primer impulso reformista de Carlos III (1766-69), bien para formar a los abogados de la Real Audiencia (Puig Gelabert, 1784), a los oficiales de la Hacienda (Cátedra de Economía Civil de la Sociedad Aragonesa de Amigos del País, 1784) o a los intendentes (De la Torre, 1776). Este rápido resumen no tiene otra pretensión que señalar la necesidad de un uso adecuado de las fuentes en función de su origen y de remitir a la lectura del autor citado y a su bibliografía a quien entre en esta senda.

Por otra parte, es importante constatar la ausencia del concepto de policía médica o Medizinischen Polizei en ambos trabajos. Este concepto fue formulado también en el territorio germánico por Rau (1764) y otros, y sistematizado por J.P.Frank (1779). Hizo su llegada a la península, básicamente, a través de autores alemanes y Vicente Mitjavila le dedicó, en el marco del proyecto global de renovación de la Medicina iniciado años antes por Jaume Bonells, un trabajo publicado en 1803, que aún necesita ser analizado. En el Compendio de Mitjavila hallamos, desde el punto de vista médico, muchos de los aspectos tocados en los trabajos de Fraile y Anguita, adelantando además el proceso de especialización de la ciencia de la policía en su proceso de desintegración.

En cuanto a la interpretación foucaultiana de la policía que hace Fraile, resulta conveniente hacer una rápida observación. Parece poco adecuado relacionar las múltiples materias del buen gobierno con la idea de disciplinar a la sociedad y configurar actitudes, así como presentar dicha relación como la cara modernizadora que acercaría la policía a la orientación represiva ochocentista. No sólo porque la aplicación de tal teoría significa caer en generalizaciones excesivas que hacen perder de vista la compleja y diversa realidad social, sino también porque tal política de detalle que en Fraile escapa a cualquier contraste documental suficiente, se correspondía más con una regulación secular autosostenida que eludía la autorregulación de la sociedad estamental, que con un objetivo socio-político predeterminado. Además, la incapacidad manifiesta del estado borbónico a lo largo del siglo XVIII y buena parte del siglo XIX para hacer observar la legislación estatal que se imponía en los reglamentos municipales o para controlar el tejido social local obliga al investigador, en todo caso, a descender al análisis particularizado de cada realidad urbana para poder establecer primeramente parámetros comparativos.

2 Véase: Ernest Lluch, El pensament econòmic a Catalunya, 1760-1840. Els origens ideològics del proteccionisme $i$ la presa de consciencia de la burgesia catalana, Barcelona, Edicions 62, 1973; «El cameralismo ante la España de Carlos III: influencia y contraste» en Carlos III y la Hacienda Pública, Hacienda Pública Española, 2 (1990), 73-86; La Catalunya vençua del segle XVIII. Foscors i clarors de la Il-lustració, Barcelona, Edicions 62, 1996. 


\section{ENSAYOS}

Finalmente, cabe destacar el escaso recurso a la historia comparada en ambos trabajos. Tal vez habría sido de gran utilidad, en el caso de Fraile, comprobar si los tratados de policía o de ciencia de la policía estuvieron en la base del discurso urbanístico en Francia o en países germánicos, así como examinar si la historiografía reciente de dichos lugares se ha hecho eco de ello en forma de monografías como las de Harouel o Lepetit ${ }^{3}$. En cuanto al trabajo de Anguita se echa de menos un análisis comparativo con los diversos procesos de crecimiento urbano en Europa y con la aplicación de las regulaciones edificatorias o urbanísticas en ellos.

En definitiva, creo que estamos ante dos trabajos cuya lectura puede resultar estimuladora para el/la historiador/a de la medicina. No sólo por los objetos de análisis histórico, que bien merecen una aproximación desde este punto de vista, sino especialmente por las vías de trabajo que aún están por explorar. En la difícil unión del discurso teórico, la ley u ordenanza y la realidad práctica y cotidiana, la historia de la medicina debe intentar comprender cuál fue la importancia de las ideas médicas en el discurso urbanístico desde el siglo XIII en relación con los oficiales locales; qué impacto tuvo la idea de policía médica, de qué fuentes se nutrió, cómo se define el proyecto mayor en que se imbricaba y cómo se relacionó con la ética médica y con la medicina legal; hasta dónde llegaban los intereses del partido higienista relacionados con las instituciones de poder locales en el proceso de transformación de las grandes ciudades de mediados del siglo XIX y hasta qué punto se puede hablar de responsabilidad profesional en sus actitudes. Cuestiones abiertas a la espera de respuestas contrastadas.

3 Bernard Lepetit, The Pre-Industrial Urban System, France, 1740-1840. Cambridge, Cambridge University Press, 1994; y J-1- Harouel, L'embellissement des villes: l'urbanisme français au XVIIIe si cle, París, Picard, 1994. 